\title{
Alternativas de tRAdUÇÃo DO JAPONÊS PARA O PORTUGUÊS: DE KODOMO No HI A DIA DAS CRIANÇAS ${ }^{*, * *}$ Translation alternatives from Japanese into Portuguese: from Kodomo no Hi to Dia das Crianças
}

\author{
Rodrigo Moura Lima de Aragão**
}

\begin{abstract}
RESUMO
Este trabalho apresenta e discute alternativas de tradução do conto japonês Kodomo no $\mathrm{Hi}$, da escritora japonesa Teriko. Primeiro, procede-se à exposição de alguns pressupostos sobre a tradução literária e discorre-se especificamente acerca da tradução literária do japonês para o português. Em seguida, são apresentados o conto japonês escolhido para este estudo e sua tradução para a língua portuguesa, Dia da Crianças. Depois, as alternativas do trabalho de tradução realizado são discutidas e, por último, encerra-se o artigo com algumas considerações gerais a respeito deste estudo.

Palavras-chave: tradução japonês-português; tradução de prosa japonesa; tradutologia de língua japonesa.
\end{abstract}

Agradece-se à escritora Teriko, por autorizar o uso de seu texto neste estudo, à professora e tradutora Shirlei Lica Ichisato Hashimoto, pelos comentários e sugestões preciosos que possibilitaram o aprimoramento deste manuscrito, à ilustradora Tomomi Aragão, pelas belas ilustrações em estilo japonês que dão cor a este trabalho, e aos pareceristas anônimos da Revista Letras, pelos apontamentos valiosos que também contribuíram para aperfeiçoar este manuscrito.

* A transcrição da língua japonesa em caracteres romanos segue aqui o sistema Hepburn, conforme descrito no Michaelis: dicionário prático japonês-português (WAKISAKA, 2003). Toda sílaba com a letra "r" tem o som de "r" como na palavra "cura", toda sílaba com "h" tem o som de "rr" como na palavra "carro", toda sílaba com "ch" tem o som de "tch" como na palavra "tchau", toda sílaba com "j" tem o som de "dj" como na palavra "adjacente", toda sílaba com "g" tem o som de "g" como na palavra "gato"; ainda, mácrons sobre as vogais sinalizam um alongamento nos sons. Quanto à transcrição das partículas japonesas “は”, “へ” e “を”, que não é detalhada no dicionário citado, adotou-se o seguinte padrão: “は” foi transcrito como "wa", “へ” foi transcrito como " $e$ " $\mathrm{e}$ " を", como "o".

FFLCH-USP. 


\begin{abstract}
This work presents and discusses alternatives to the translation of the Japanese short story Kodomo no Hi by the Japanese writer Teriko. Firstly, some presuppositions on literary translation are presented, and literary translation from Japanese to Portuguese is specifically discoursed upon. Next, the Japanese short story chosen for this study and its translation into Portuguese, Dia das Crianças, are presented. Then, the alternatives of the translation work carried out are discussed, and finally general thoughts on this study finish the article.
\end{abstract}

Key-words: Japanese-Portuguese translation; Japanese prose translation; Japanese language traductology.

\title{
INTRODUÇÃO
}

No Brasil, a tradução para a língua portuguesa de textos produzidos em japonês parece bem estabelecida enquanto campo de atividade profissional. Nos sítios e prateleiras das grandes livrarias do país, é possível encontrar obras traduzidas de inúmeros autores japoneses - como Sōseki Natsume, Ryūnosuke Akutagawa, Yasunari Kawabata e Haruki Murakami-, o que sinaliza a existência de um segmento de mercado que atrai a atenção das editoras e, consequentemente, provoca uma demanda por tradutores de língua japonesa no Brasil ${ }^{1}$. Ainda, há uma grande quantidade de empresas japonesas atuantes no país (como Toyota e Honda) que geram também demanda por esses profissionais, uma vez que muitos de seus materiais escritos (por exemplo, manuais) precisam ser traduzidos para a língua portuguesa.

Quando o assunto são estudos sobre a tradução do japonês para o português, no entanto, o cenário é, aparentemente, outro. Embora haja um grande número de trabalhos acadêmicos que contêm traduções de textos literários japoneses (HASHIMOTO, 1986; SHIMON, 1998; NAGAE, 1999; etc.), o foco de suas análises não é a tradução propriamente. Estudos que versam especificamente a respeito da tradução da língua japonesa para a portuguesa são, de fato, em número reduzido no Brasil - tem-se conhecimento apenas do artigo de Batista (1994), que aborda a tradução de poesia japonesa, e da dissertação de Waragai (2008), que trata de interferências culturais na

1 Essa afirmação pode parecer suspeita, pois deduz da comercialização de livros um segmento de mercado. Contudo, sob uma ótica de negócios, sabe-se que, sem um segmento de mercado atraente que justifique o investimento das editoras, essas obras não estariam disponíveis nas grandes livrarias brasileiras. 
tradução de textos religiosos japoneses,$-^{2}$ não sendo exagero falar que existe um longo caminho a ser percorrido ainda pelos pesquisadores que têm interesse pelo tema no país ${ }^{3}$.

Este trabalho dirige-se a essa lacuna e tem como proposta a apresentação e a discussão de alternativas de tradução de um conto da escritora japonesa Teriko, Kodomo no Hi. Trata-se de um esforço que transita nos limites da consolidação, da construção e da desconstrução de paradigmas de tradução, uma vez que, seja para reforçar o que vem sendo feito, seja para propor novos ou derrubar velhos fazeres tradutórios, uma abordagem fundamental é esta: traduzir e, por meio do debate, da discussão, sustentar escolhas. É nesse sentido que se desenvolve este trabalho.

\section{Pressupostos Sobre A tRAdução LITERÁRIA}

Landers (2001, p. 49, tradução nossa) afirma que "A maior parte dos tradutores avalia o êxito de uma tradução principalmente com base no quanto "sua leitura não parece com a de uma tradução". Nesse caso, segundo o autor, "O objetivo é expressar a língua A na língua B de um modo que deixe o mínimo de evidência possível do processo [tradutório]"4.

Discorda-se dessa corrente que defende a mínima diferença (ou a máxima semelhança) do produto do trabalho de tradução literária para uma dada língua com o produto do trabalho de criação literária que se dá originalmente nessa língua. De certa forma, alinha-se aqui à posição de Pannwitz (apud BENJAMIN, 1992, p. 81, tradução nossa), quando este afirma que:

O erro básico do tradutor é que ele preserva o estado no qual sua própria língua se encontra, em vez de permitir que sua língua seja

2 Pode ser questionado se o trabalho de Haroldo de Campos (2006), Hagoromo de Zeami, não seria também um estudo sobre a tradução da língua japonesa para a portuguesa. Contudo, embora esse trabalho faça diversas referências a opções de tradução e ainda que contenha, sim, uma tradução (KUSANO; DOI, 2006), o seu produto é uma "transcriação" (CAMPOS, 2006, p. 26 e 35), ou "reinvenção" (CAMPOS, 2006, p. 18), e não uma tradução propriamente. Isso o afasta do que se entende aqui por estudos de tradução.

Em exposição que compôs uma mesa-redonda sobre tradução no XVII Encontro Nacional de Professores Universitários de Língua, Literatura e Cultura Japonesa, Nagae (2006, p. 113) afirma mesmo que "[...] os estudos tradutórios no caso do japonês ainda não [...] parecem ter sido iniciados".

Trecho original em inglês: "Most translators judge the success of a translation largely on the degree to which it 'doesn't read like a translation'. The object is to render Language A into Language B in a way that leaves as little evidence as possible of the process" (LANDERS, 2001, p. 49). 
fortemente afetada pela língua estrangeira. Especialmente nos casos em que traduz de uma língua muito remota da sua, ele deve retornar aos elementos fundamentais da língua em si e alcançar o ponto no qual trabalho, imagem e tom convergem. Ele deve expandir e aprofundar sua língua por meio da língua estrangeira ${ }^{5}$.

No trabalho de tradução de textos literários, entende-se que deve haver um pouco de permeabilidade quanto aos recursos linguísticos dos originais, de sorte a preservar o foco no texto e contexto alienígenas, principal atrativo da tradução - um pouco de, e não total permeabilidade; do contrário, a inteligibilidade é prejudicada.

Além do mais, avalia-se que o trabalho de tradução literária requer um compromisso básico do tradutor: transparência. Sobretudo na tradução de textos escritos em línguas remotas, como é o caso do japonês em relação ao português, o tradutor procede a operações de adaptação em seu texto para expressar um dado elemento ou aspecto que é particular da língua de partida. Ainda, muitas vezes esse aspecto ou elemento é simplesmente deixado de lado, porque não foram identificados recursos adequados para sua expressão na língua de chegada. Há mesmo situações em que é necessário tornar explícito na tradução um elemento implícito do original, como, por exemplo, quando há diferenças na transitividade dos verbos de uma língua e de outra - quando o verbo da língua de partida não requer complemento, e o da língua de chegada, $\operatorname{sim}^{6}$. Em casos como esses, considera-se mister comunicar ao leitor o que foi feito - ainda que de maneira abreviada -, de modo a não transmitir uma imagem distorcida do original (transparência).

\section{TRADUÇÃo LITERÁRIA DO JAPONÊS PARA O PORTUGUÊS}

Se comparado com línguas como o espanhol, o francês, o italiano e mesmo o inglês, o japonês situa-se distante da língua portuguesa. Essa distância tem implicações importantes para o trabalho do tradutor, porque

$5 \quad$ Trecho original em inglês: "The basic error of the translator is that he preserves the state in which his own language happens to be instead of allowing his language to be powerfully affected by the foreign tongue. Particularly when translating from a language very remote from his own he must go back to the primal elements of language itself and penetrate to the point where work, image, and tone converge. He must expand and deepen his language by means of the foreign language" (PANNWITZ apud BENJAMIN, 1992, p. 81).

6 Um exemplo disso que aparece na tradução realizada refere-se ao verbo japonês "kazaru", que não exige complemento, e ao seu correspondente português "enfeitar", que requer complemento (é preciso explicitar em português o que é/foi/será enfeitado). 
o coloca diante de um grande número de passagens de difícil expressão no português. É digno de nota o título escolhido por Seidensticker (1989, p. 142), tradutor famoso por seu trabalho com a obra clássica japonesa Genji Monogatari, para um de seus textos sobre tradução: "On trying to translate Japanese" ("Sobre tentar traduzir o japonês", tradução nossa). Esse título sugere que o japonês não é uma língua que se traduz, mas uma língua que se tenta traduzir.

Caso se interprete a tradução como uma prática restrita à conversão de palavras e expressões de uma língua para outra, não é exagero dizer que, em muitas situações, a língua japonesa não pode, de fato, ser traduzida, apenas interpretada ou adaptada. Assume-se, contudo, uma posição mais abrangente quanto à tradução: entende-se que esta envolve um grande número de operações, que vão desde a conversão de palavras e expressões até o emprego de diferentes recursos na elaboração do texto na língua de chegada para a expressão de aspectos particulares da língua de partida (adaptação). Especificamente no que diz respeito à tradução de textos literários do japonês para o português, reconhecem-se ao menos oito operações básicas:

1) Conversão de itens lexicais e gramaticais: implica a escolha do(s) vocábulo(s) da língua portuguesa mais adequado(s) para expressar um dado item lexical ou gramatical japonês; implica, ainda, a opção pela flexão portuguesa mais apropriada para expressar os itens flexionados e não flexionados japoneses;

2) Supressão de itens gramaticais: consiste na eliminação dos itens gramaticais da língua japonesa que não têm correspondentes no português. Por exemplo, na tradução para o português da sentença "Kanada-san wa atarashii kuruma o kaimashita", as partículas "wa" e "o" são eliminadas: "Kanada-san comprou um carro novo";

3) Reordenação sintática: trata-se da alteração da ordem dos componentes das sentenças (nem sempre necessária). Por exemplo, é comum no japonês a sequência "Sujeito + Complemento + Verbo", como na frase "Sakura-san ga Burajiru e ikimasu". Em casos como este, a tradução para o português requer a alteração para a sequência "Sujeito + Verbo + Complemento": "Sakura-san vai para o Brasil";

4) Adição de itens lexicais e gramaticais: envolve a inclusão de itens lexicais e gramaticais da língua portuguesa que são necessários, sobretudo, para que a tradução não fique lógica, semântica ou gramaticalmente incompleta. Por exemplo, na tradução para o português da sentença "Attsui!", é preciso incluir ou o verbo "estar", ou o verbo "estar" mais a preposição "com”, ou o prono- 
me "que": "Tá calor!", "Tô com calor!" ou, ainda, "Que calor!". É conveniente indicar ao leitor a adição de itens lexicais que ultrapassa os limites do explícito/óbvio e do indispensável com colchetes ou outros recursos (transparência);

5) Transcrição de itens lexicais: trata-se da incorporação de itens lexicais japoneses à tradução em língua portuguesa. Por exemplo, o sufixo de tratamento japonês "-san" foi incorporado à tradução nos itens 2) e 3), acima. Outros exemplos incluíriam o emprego, na tradução, de "tôfu" no lugar de "queijo de soja" e de "hashi" no lugar de "pauzinhos";

6) Adaptação: consiste no emprego de um dado recurso na tradução em língua portuguesa para transmitir elementos/aspectos dos textos japoneses que são expressos ou por recursos ausentes no português, ou por rimas, jogos de palavras, etc. Por exemplo, na tradução da sentença "Mō hachi ji han da yo", a partícula "yo" não pode ser convertida para o português ${ }^{7}$, apenas suprimida ou adaptada. No caso da adaptação, um ponto de exclamação poderia ser usado para produzir um efeito parecido (mas não equivalente) ao da sentença original: "Já são 8 e meia!";

7) Reunião e apresentação de informações relacionadas ao conteúdo da obra: trata-se da reunião de informações relevantes para a compreensão do texto japonês e de sua anexação na tradução na forma de notas explicativas, glossários, etc.;

8) Síntese e apresentação de informações relacionadas ao trabalho de tradução: consiste na síntese e apresentação ao leitor de informações relacionadas ao trabalho de tradução, sobretudo no que diz respeito às adaptações realizadas e às perdas de aspectos do original observadas pelo tradutor - também as informações referentes à adição de itens lexicais podem ser encaixadas aqui.

KODOMO NO HI, DE TERIKO

O conto escolhido para este trabalho foi Kodomo no Hi, da escritora japonesa Teriko. O contato com esse conto se deu por meio da comunidade

É interessante observar que há autores que afirmam que a partícula japonesa " $y o$ ", quando usada no final de sentenças, não pode ser traduzida - como, por exemplo, Kawashima (1992, p. 251).

8 Note-se que, aqui, faz-se essa adaptação imaginando uma situação na qual o falante mostra-se insatisfeito com a demora do ouvinte. Sabe-se, contudo, que, em outras situações, o ponto de exclamação pode não ser um recurso adequado para expressar a partícula "yo". 
eletrônica literária DNovels, espaço virtual de exposição, leitura e discussão dos mais variados gêneros em língua japonesa que tem como slogan a frase "Subete no hito wa monogatari de tsunagaru" (DNOVELS, 2010), isto é, "Todas as pessoas se conectam por histórias" (tradução nossa). Entre os fatores que motivaram a escolha de Kodomo no Hi para este estudo, podem ser citados como principais: 1) o conto aborda um feriado cujas tradições e costumes diferem largamente do que ocorre no Brasil na data comemorativa correspondente e, portanto, é interessante para a discussão do trabalho de tradução; 2) o conto compreende aspectos da língua japonesa de difícil expressão no português e, por isso, é apropriado para a discussão de tópicos relacionados à tradução; 3) a extensão de Kodomo no Hi é adequada para a composição de um trabalho acadêmico de apresentação e discussão de alternativas de tradução.

A seguir, apresenta-se a transcrição de Kodomo no Hi (primeiro, em caracteres japoneses e chineses e, depois, em caracteres romanos $)^{9}$.

$$
\text { こどもの日 }
$$

「ママ。ちーちゃんもこいのぼりほしいよ」

住宅街の、あちこちの家に鯉のぼりが飾られているのを見て、 娘がわたしの腰に抱きついてきておねだりをはじめた。

「え? こいのぼりは、男の子のためのお祝いなのよ」

「どーして?」

「ほら、3 月 3 日は女の子のお祝いでお雛樣飾ったでしょ？

だから 5 月 5 日は男の子のお祝いで、鯉のぼりを飾るんだよ」

ちーちやんは女の子でしょ？ と視線で訴えるが、娘は納得

していない。

「だって。 5 がつ 5 にちは、こどものひだよ？おととのこも おんなのこもこどもだよ」

うわ。いつの間にこんなに口達者になったのだろう。男の子 ときちんと発音できないのに、幼稚園に行くといろんなことを 覚えてくるんだ。

などと感心してられない。娘はしがみついたまま、じーっと 見上げてくる。納得いく返事をもらうまで離さないぞと訴えて るよ、この目。

えーと。どうして端午の節句をこどもの日って言うようにな ったんだろう?

とにかく鯉のぼりは男の子の成長を願うものなんだよね。

「こいのぼりは、男の子が元気に大きくなるようにお願いして いるんだから、ちーちゃんには関係ないの。こどもの日は、お 休みの名前だから、鯉のぼりとは別なの」

9 A publicação de Kodomo no Hi neste artigo foi autorizada por sua autora, contudo, os direitos autorais do conto permanecem em sua posse. 


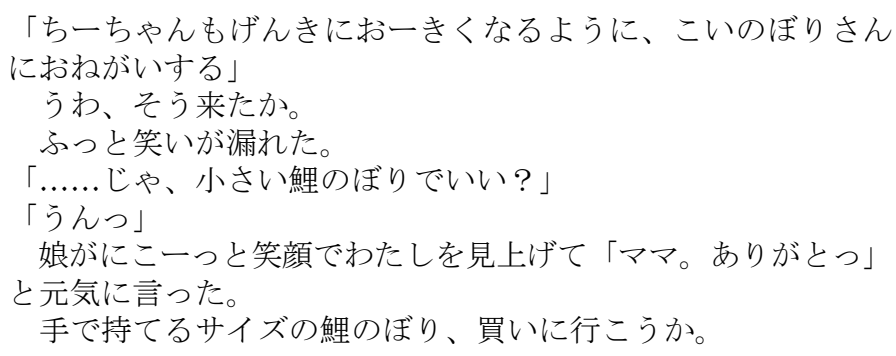

\section{Kodomo no $\mathrm{Hi}^{10}$}

"Mama. Chī-chan mo koinobori hoshii yo"

Jūtakugai no, achikochi no ie ni koinobori ga kazarareteiru no o mite, musume ga watashi no ude ni dakitsuitekite onedari o hajimeta.

"E? Koinobori wa, otoko no ko no tame no o-iwai na no yo" "Dōshite?"

"Hora, sangatsu mikka wa onna no ko no o-iwai de o-hina-sama kazatta desho? Dakara gogatsu itsuka wa otoko no ko no o-iwai de, koinobori o kazarunda yo"

Chì-chan wa onna no ko desho? to shisen de uttaeru ga, musume wa nattokushiteinai.

"Datte. Gogatsu gonichi wa, kodomo no hi da yo? Ototo no ko mo onna no ko mo kodomo da yo"

Uwa. Itsu no ma ni konna ni kuchidassha ni natta no darō. Otoko no ko to kichinto hatsuondekinai no ni, yōchien ni iku to ironna koto o oboetekurunda.

Nado to kanshinshiterarenai. Musume wa shigamitsuita mama, jītto miagetekuru. Nattokuiku henji o morau made hanasanai zo to uttaeteru yo, kono me.

Ėto. Dōshite tango no sekku o kodomo no hitte iu yō ni nattandarō?

Tonikaku koinobori wa otoko no ko no seichō o negau mono nanda yone.

"Koinobori wa, otoko no ko ga genki ni ōkiku naru yōni onegaishiteirunda kara, Chī-chan ni wa kankei nai no. Kodomo no hi wa, oyasumi no namae da kara, koinobori to wa betsu na no"

"Chī-chan mo genki ni ōkiku naru yō ni, koinobori-san ni onegaisuru"

Uwa, sō kita ka.

Futto warai ga moreta.“......ja, chiisai koinobori de ii?”

10 Nesta transcrição, as aspas correspondem aos colchetes japoneses, “「」”. Ainda, a supressão de sons no final de palavras que é feita no japonês com “つ” é representada pelo apóstrofo. 


\author{
"Un" \\ Musume ga nikōtto egao de watashi o miagete "Mama. \\ Arigato"' to genki ni itta. \\ Te de moteru saizu no koinobori, kai ni ikō ka.
}

(Ryō)

\title{
DIA DAS CRIANÇAS
}

Nesta seção, apresenta-se a tradução para a língua portuguesa de Kodomo no Hi, Dia das Crianças, segundo a acepção de tradução assumida, ou seja, apresentam-se aqui, além do texto de Teriko em português, informações relacionadas ao conteúdo do conto ("Prólogo do tradutor" e "Glossário") e informações relacionadas ao trabalho de tradução ("Nota do tradutor").

\section{PRÓlogo do TRADUTOR}

No Japão, há duas grandes festividades relacionadas com as crianças: o Festival dos Meninos (Tango no Sekku), comemorado no dia 5 de maio, e o Festival das Meninas (Hina Matsuri), comemorado no dia 3 de março. No Festival dos Meninos, os japoneses têm o costume de enfeitar a parte externa das casas com os koinobori, enfeites em forma de carpa que balançam com o vento, com o intuito de pedir saúde para os meninos. Em geral, os koinobori são hasteados de modo a compor uma série vertical, como na primeira ilustração da página seguinte.

Já no Festival das Meninas, os japoneses enfeitam o interior de suas casas com as o-hina-sama (ou hina-ningyō), bonecas que servem para pedir a saúde das meninas. As o-hina-sama representam o imperador, a imperatriz e os membros da corte do Japão da Era Heian (de 794 a aproximadamente 1185 d.C.) e são colocadas, em geral, em uma estrutura com degraus, de modo a retratar a hierarquia social da época. Na segunda ilustração da página seguinte, as o-hina-sama representam o imperador e a imperatriz do Japão da Era Heian.

Embora haja duas grandes festividades relacionadas com as crianças no Japão, o curioso é que o Dia das Crianças, feriado nacional japonês, restringe-se ao dia 5 de maio, isto é, à data do Festival dos Meninos. Mais curioso ainda é o fato de que, apesar de receber o rótulo de "Dia das Crianças", esse feriado é mantido como uma data de celebração exclusiva dos meninos. $\mathrm{O}$ conto de Teriko, leve e fluido, toca nesse ponto. 


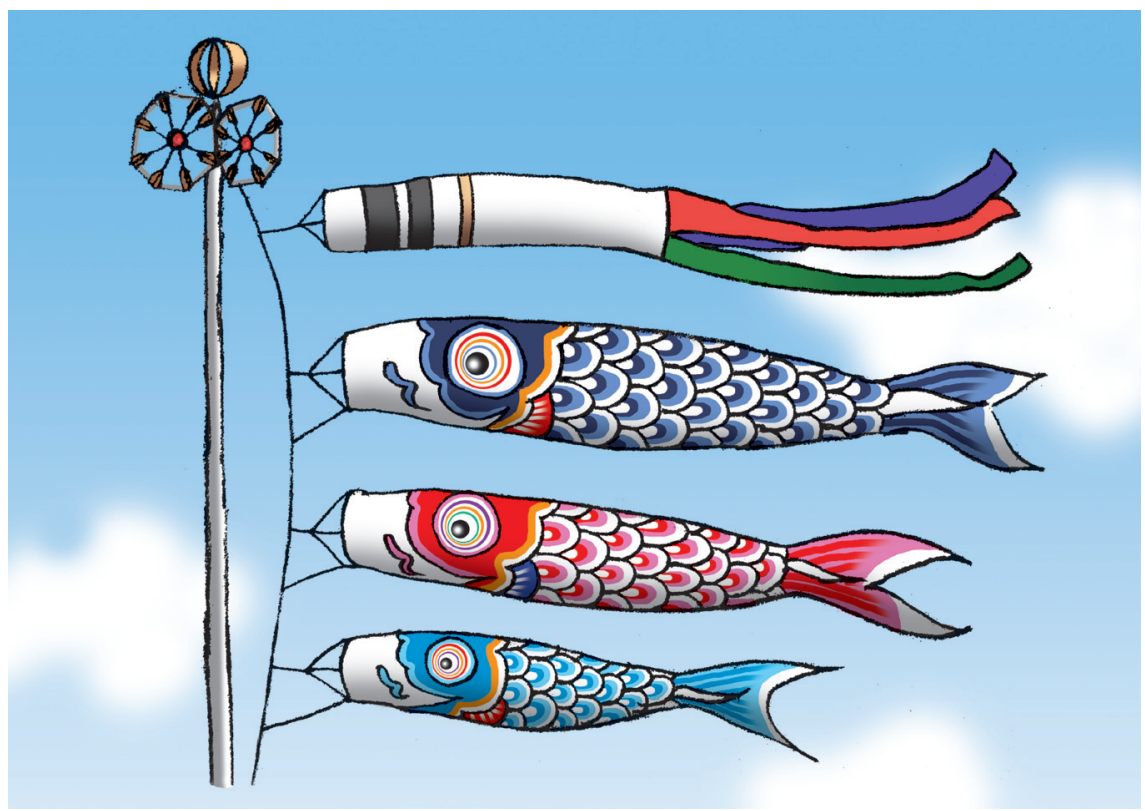

Koinobori (ilustração de Tomomi Aragão, cortesia da ilustradora).

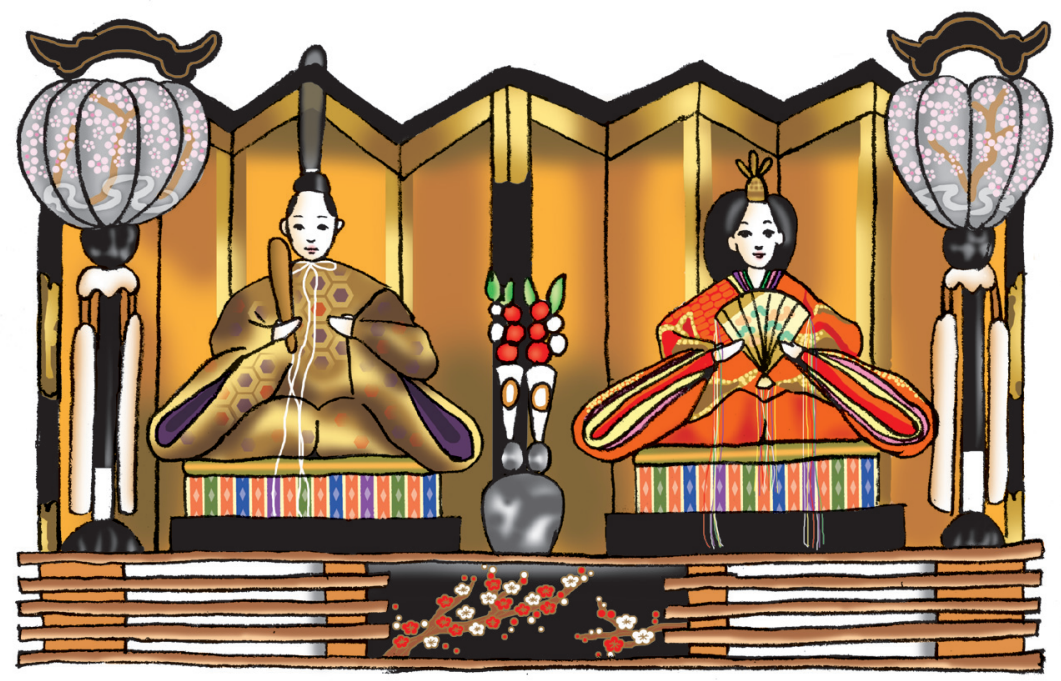

O-hina-sama representando o imperador e a imperatriz do Japão da Era Heian (de 794 a cerca de 1185 d.C.) (ilustração de Tomomi Aragão, cortesia da ilustradora). 
GLOSSÁRIO

-chan. /t $\int a n /$ Sufixo de tratamento japonês que denota proximidade ou afetividade. Em geral, é usado no Japão com nomes ou apelidos de crianças ou jovens do sexo feminino. Por exemplo: "Tomiko-chan", "Mai-chan", "Sakura-chan". Não existe um correspondente na língua portuguesa, mas seu efeito de sentido é similar àquele que se obtém quando se usa o diminutivo para chamar ou se referir a meninas ou moças brasileiras, como em "Raquelzinha", "Renatinha", "Rêzinha" e "Mariazinha".

-san. /san/ Sufixo de tratamento japonês que denota respeito. Em geral, é usado no Japão com sobrenomes de adultos japoneses. Por exemplo: "Satō-san", "Yamada-san", "Yamaguchi-san". Não há um correspondente no português, no entanto, seu efeito de sentido é próximo àquele que se obtém com o emprego de "senhor", como em "Senhor Morais". Ainda, é bastante usado por crianças japonesas para fazer referência a animais, como em "kuma-san" ("urso-san") e "zō-san" ("elefante-san"). Nesse caso, contudo, -san confere à linguagem um tom infantil (é um modo de falar das crianças), não tendo a ver com a expressão de respeito.

\section{Dia das Crianças}

1

- Mamãe. A Chī-chan também quer um koinobori.

A minha filha viu que os koinobori enfeitavam as casas daqui e dacolá de um bairro residencial e, então, se agarrou na minha cintura e começou a me azucrinar.

- O quê? O koinobori é um enfeite de celebração para os MENINOS, ouviu?

- Por quê?

- Lembra, no dia 3 de março a gente enfeitou a casa com as o-hina-sama como uma celebração das meninas, não foi? Então, no dia 5 de maio enfeitam-se as casas com os koinobori como uma celebração dos MENINOS.

Eu protesto com o olhar, como se dissesse "A Chī-chan é uma menina, não é mesmo?”, mas minha filha não se convence.

- Mas... 5 de maio é Dia das Crianças, não é? Os meninos e as meninas são crianças!

Nossa! Antes que eu me desse conta ela se tornou assim tão eloquente? Apesar de ainda não conseguir pronunciar corretamente algumas palavras, foi só ir ao jardim-de-infância que passou a aprender um montão de coisas.

Mas não é hora de ficar assim admirada. Minha filha, ainda agarrada à minha cintura, ergue os olhos fixamente. "Não vou largar até receber uma 
20

resposta convincente!”, apela esse olhar.

Bem... Por que será que o Festival dos Meninos passou a ser chamado de "Dia das Crianças"?

De qualquer forma, koinobori é algo pra pedir o crescimento dos meninos, não é mesmo?...

5 - Como o koinobori tá pedindo que os meninos fiquem grandes com saúde, não tem a ver com a Chī-chan, ouviu? "Dia das Crianças" é o nome do feriado; por isso, koinobori é outra coisa, tá bom?

- Se é assim, vou pedir pro koinobori-san pra Chī-chan também ficar grande com saúde.

Puxa, foi assim que respondeu?

Um sorriso escapou sem querer.

- Hum... Então, pode ser um koinobori pequenininho?

- Sim.

A minha filha ergueu os olhos pra mim com um rosto sorridente e, com disposição, disse: - Mamãe. Brigada.

Um koinobori de um tamanho que caiba na mão, então, vamos comprar?

(Fim)

NotA Do TRADUTOR

Nesta tradução, as seguintes adaptações foram realizadas: a) letras maiúsculas, sinais de pontuação e marcadores conversacionais (como "ouviu?" e "tá bom?") foram usados para conferir ao texto português efeitos semelhantes aos conferidos ao original japonês com o uso das partículas japonesas "yo", "yone", "no" e "ka"; b) no original japonês, Chī-chan pronuncia incorretamente a palavra "otoko no ko" ("meninos") - ela diz "ototo no ko" - e sua mãe faz referência a essa pronúncia, tendo sido realizada uma adaptação ao não se incluir uma pronúncia incorreta na fala de Chīchan das linhas 13 e 14 e ao se escrever "algumas palavras" no raciocínio da personagem mãe na linha 16 .

Além disso, os seguintes itens foram adicionados nesta tradução: "casa" (linha 8), "as casas" (linha 10), "Eu" (linha 11), "como se dissesse" (linha 11), "ela" (linha 15), "ainda" (linha 16), "Mas" (linha 18), "à minha cintura" (linhas 18 e 19), "Se é assim" (linha 28), “, então," (linha 36). (Note-se que estão listados aqui apenas os itens cuja adição na tradução é dispensável ou pouco óbvia).

Por último, as seguintes perdas podem ser constatadas nesta tradução, se for realizado um contraste com o texto original japonês: a) a 
expressão da qualidade de criança de Chī-chan que se dá com o uso exclusivo dos silabários japoneses hiragana e katakana no texto original foi perdida na tradução; b) enquanto, no texto original, as falas guardam uma relação estreita com as características das personagens (por exemplo, a fala da personagem mãe sinaliza que esta é mulher e que se trata, provavelmente, de uma mulher jovem), na tradução, percebe-se um enfraquecimento dessa relação.

\section{Alternativas De tRaduÇão - Discussão}

A seguir, as alternativas do trabalho de tradução realizado são discutidas, tendo-se como lente as oito operações básicas apontadas para a tradução de textos literários do japonês para o português.

\section{Conversão E Transcrição}

Na maior parte dos casos, as alternativas de conversão presentes na tradução de Kodomo no $H i$ provavelmente não geram debate entre os tradutores de japonês. Uma única alternativa de conversão, apenas, pode ser mais polêmica no círculo desses tradutores: a conversão do japonês "Ch $\vec{\imath}$ ", presente em duas falas da própria Chī-chan, em "Chī" no texto em português. Isso porque, nesses casos, talvez o primeiro impulso do tradutor de língua japonesa seja converter "Ch$\vec{\imath}$ " em "Eu". Ou seja, em vez de "A Chīchan também quer [...]" (linha 1 de Dia das Crianças), "Eu também quero [...]"; em vez de "-Se é assim, vou pedir pro koinobori-san pra Chī-chan também [...]" (linha 28), “- Se é assim, vou pedir pro koinobori-san pra eu também [...]". Na tradução realizada, contudo, optou-se pela manutenção da referência que Chī-chan faz a si mesma no texto japonês com "Chli" (no lugar de um pronome pessoal da primeira pessoa), porque se interpreta esse recurso como linguisticamente rico e relevante para a captura dos modos de expressão do Japão.

Agora, saindo da esfera das alternativas de conversão e indo para a esfera das alternativas de transcrição, cabe discutir primeiro a transcrição do sufixo de tratamento "-chan". Na realidade, outras duas opções seriam possíveis para a tradução desse elemento: a primeira seria suprimi-lo na tradução, isto é, traduzir "Chì-Chan" como "Chī" apenas; já a segunda alternativa seria usar o diminutivo para provocar um efeito em português semelhante ao efeito que confere o uso de "-chan" em japonês, ou seja, realizar uma adaptação de "Chì-chan" para "Chīzinha". Na tradução, contudo, optou-se 
não pela supressão, nem pela adaptação, mas pela transcrição. Isso decorre da leitura de que os sufixos de tratamento da língua japonesa são elementos importantes para a compreensão da manifestação dos papéis sociais japoneses no discurso, uma vez que indicam aproximação e distanciamento entre os falantes, níveis de formalidade e posições nas hierarquias sociais japonesas. Dessa forma, a supressão de "-chan" levaria a uma perda na tradução, porque essa indicação seria apagada. De outro modo, caso a opção fosse pela adaptação, não haveria perda, todavia, posiciona-se a favor de traduções (moderadamente) permeáveis e, por isso, transcreveu-se "-chan".

Além desse sufixo, outros três itens foram transcritos na tradução apresentada: "koinobori", "o-hina-sama" e "-san". Quanto aos dois primeiros, sua transcrição decorre da percepção de que esses itens são: a) termos-chave para a compreensão do conto; e b) termos-chave cujas possibilidades de conversão para o português não capturam todo o significado expresso em língua japonesa. Já quanto ao sufixo "-san", sua transcrição se deve à leitura de que, em Kodomo no Hi, esse item desempenha um papel importante na caracterização da personagem Chī-chan (é um indicativo ou intensificador de sua qualidade de criança) e, ainda, à leitura de que, no texto em português, sua incorporação proporciona melhores resultados em termos de fidelidade ao original do que sua supressão ou algum tipo de adaptação.

\section{REORDENAÇÃo SINTÁTICA}

A partir do contraste entre o original japonês de Teriko e a tradução para o português apresentada, é possível observar que a alteração da ordem dos componentes das sentenças (reordenação sintática) foi realizada em quase todos os casos em que essa modificação se faz necessária. Manteve-se a ordem "Complemento + Verbo" de uma sentença do conto apenas, a última, "Te de moteru saizu no koinobori, kai ni ikō ka": em vez de "Vamos comprar, então, um koinobori de um tamanho que caiba na mão?", optou-se por "Um koinobori de um tamanho que caiba na mão, então, vamos comprar?", com o uso daquilo que Bechara (2009, p. 595) chama de "antecipação".

Justifica-se essa opção pelo efeito que essa figura de linguagem confere à sentença em língua portuguesa, que é similar ao do original japonês. Em "Te de moteru saizu no koinobori, kai ni ikō ka", o verbo encontra-se no final da frase, sendo mantido, portanto, o suspense do conto até o último momento - afinal, a tensão de Kodomo no Hi se concentra na tentativa de convencimento de Chī-chan para obter o koinobori, e o que encerra a trama é justamente a informação de que esse convencimento foi bem-sucedido, isto é, a indicação de que a mãe vai comprar o artefato ("kai ni ikō ka"). Em português, caso a opção fosse por "Vamos comprar, então, um koinobori de 
um tamanho que caiba na mão?", o suspense do conto acabaria no início da sentença e, por isso, empregou-se a antecipação.

Reconhece-se, contudo, que esse recurso talvez não soe tão natural ao leitor brasileiro, mas posiciona-se aqui a favor da incorporação moderada da ordem dos elementos que constituem uma sentença japonesa nas traduções em língua portuguesa, de modo a conferir a essas traduções uma tonalidade vermelha e branca mais expressiva. Ainda, destaca-se que a ordem "Complemento + Verbo", se rara no português escrito, aparece, sim, no português falado - cf. Pontes (1987) e Callou et al. (2002) -, podendo o seu uso nas traduções de textos literários japoneses, portanto, ser considerado como uma alternativa de tradução, especialmente nos casos em que há marcas de oralidade nos originais, como é o caso de Kodomo no Hi.

\section{AdIÇÃo E SUPRESSÃo}

Quanto às adições e supressões realizadas, o único ponto que merece atenção é a indicação que se fez, na "Nota do tradutor", das adições menos óbvias ou dispensáveis. Se a adição de itens na tradução com fins principalmente de natureza lógica, semântica e estilística pode ser interpretada como uma transgressão ao original em termos de fidelidade, sua indicação ao leitor tem o poder de anular esse aspecto negativo e, consequentemente, possibilita ao tradutor mais liberdade. Defende-se esse tipo de adição como um meio para tornar a leitura da tradução mais fluida, desde que haja sua indicação ao leitor - transparência.

\section{ADAPTAÇÃo}

Operações de adaptação foram realizadas, primeiro, para expressar no texto em português as seguintes partículas japonesas que aparecem no final de sentenças: "yo", "yone", "ka" e "no". Basicamente, essas operações envolveram três etapas: 1) identificação das funções dessas quatro partículas na literatura que aborda as partículas japonesas; 2) verificação das funções desempenhadas por essas partículas em Kodomo no $\mathrm{Hi}$; 3) identificação e emprego de recursos que pudessem desempenhar, no texto em português, funções semelhantes àquelas observadas no original japonês.

O Quadro 1, a seguir, apresenta as funções das partículas identificadas na literatura e em Kodomo no $\mathrm{Hi}$, os recursos empregados no texto em português para expressar essas partículas e exemplos do uso desses recursos em Dia das Crianças. 
QUADRO 1 - Funções das partículas "Yo", "YonE", “KA" E "NO" identificadas na literatura e em Kodomo no $H I$, Recursos empregados em Dia das CRianças para expressar essas partículas E EXEMPLOS DO USO DESSES RECURSOS EXTRAídos DA TRADUÇÃo REALIZADA.

\begin{tabular}{|c|c|c|c|}
\hline Partícula & Função & Recurso & Exemplo \\
\hline \multirow[t]{2}{*}{ Yo } & $\begin{array}{l}\text { Fazer o ouvinte tomar co- } \\
\text { nhecimento de algo que não } \\
\text { sabe (IORI et al., 2007a, } \\
\text { p. 167). }\end{array}$ & Maiúsculas & $\begin{array}{l}\text { "O koinobori é um enfeite de } \\
\text { celebração para os MENINOS, } \\
\text { ouviu?" (linhas } 5 \text { e } 6 \text { ) }\end{array}$ \\
\hline & $\begin{array}{l}\text { Transformar uma sentença } \\
\text { em uma exclamação (KA- } \\
\text { WASHIMA, 1992, p. 251). }\end{array}$ & Ponto de exclamação & $\begin{array}{l}\text { "Os meninos e as meninas } \\
\text { são crianças!" (linhas } 13 \text { e } \\
\text { 14) }\end{array}$ \\
\hline Yone & $\begin{array}{l}\text { Expressar uma confirma- } \\
\text { ção, sendo mais natural } \\
\text { quando o falante não tem } \\
\text { certeza do que diz (IORI et } \\
\text { al., 2007b, p. 275). }\end{array}$ & $\begin{array}{l}\text { Marcador conversa- } \\
\text { cional com reticên- } \\
\text { cias }\end{array}$ & $\begin{array}{l}\text { "De qualquer forma, koinobori } \\
\text { é algo pra pedir o crescimento } \\
\text { dos meninos, não é mes- } \\
\text { mo?..." (linhas } 23 \text { e } 24 \text { ) }\end{array}$ \\
\hline Ка & $\begin{array}{l}\text { Indicar perguntas (CHINO, } \\
\text { 1991, p. 45). }\end{array}$ & $\begin{array}{l}\text { Ponto de interro- } \\
\text { gação }\end{array}$ & $\begin{array}{l}\text { "Puxa, foi assim que respon- } \\
\text { deu?" ( linha 30) }\end{array}$ \\
\hline No & $\begin{array}{l}\text { Conferir um tom mais ame- } \\
\text { no às asserções (CHINO, } \\
1991, \text { p. } 71 \text { ). }\end{array}$ & $\begin{array}{l}\text { Marcadores conver- } \\
\text { sacionais }\end{array}$ & $\begin{array}{l}\text { "Como o koinobori tá pedindo } \\
\text { que os meninos fiquem gran- } \\
\text { des com saúde, não tem a } \\
\text { ver com a Chī-chan, ouviu?" } \\
\text { (linhas } 25 \text { e } 26 \text { ) }\end{array}$ \\
\hline
\end{tabular}

Embora se saiba que as partículas japonesas que aparecem no final de sentenças são "[...] um campo novo dentro das pesquisas em língua japonesa" e que "[...] ainda não há uma teoria estabelecida sobre o significado e função dessas partículas [...]" (IORI et al., 2007, p. 169, tradução nossa $)^{11}$, consideram-se as obras que tratam delas uma fonte válida para o trabalho de tradução. Apesar de geralmente não reunirem resultados de pesquisas baseadas em corpora, mas observações e considerações de seus autores com relação às partículas, ainda assim dá-se crédito a essas obras, recomendando-se o seu uso como suporte para a tradução de textos produzidos em japonês.

Quanto aos recursos empregados na tradução para expressar as partículas japonesas, foram consultadas gramáticas como a de Cunha e Cintra (2008) para verificar em que medida havia correspondência entre as funções das partículas japonesas e os sinais de pontuação do português, e deteve-se ainda sobre os marcadores conversacionais (URBANO, 2003), es-

11 Trecho original em japonês (IORI et al., 2007a, p. 169): "Shüjoshi wa nihongo kenkyu no naka de wa hikakuteki atarashii bun'ya desu. Koko de atsukatta 'ne' 'yo' 'yone' o fukume, sono imi ya kinō ni tsuite wa mada teisetsu to itta mono wa naku, kore kara kaimeisareteiku mono to omowaremasu". 
pecialmente úteis para a expressão das partículas japonesas "yone" e "no" No que diz respeito ao uso de maiúsculas, partiu-se da ideia de que esse recurso confere, na representação da fala, destaque às palavras, indicando uma elevação no tom de voz do falante, o que combina com alguns casos de uso da partícula japonesa "yo".

Fora as adaptações feitas para expressar as partículas japonesas que aparecem no final de sentenças, procedeu-se a uma única adaptação em Dia das Crianças: nas linhas 13 e 14, não se incluiu nenhuma falha na pronúncia de Chī-chan, diferentemente do que há no original (Chī-chan pronuncia "ototo no ko" no lugar de "otoko no ko", "meninos"), e, depois, na linha 16 , em vez de manter a referência da personagem mãe à pronúncia incorreta de Chī-chan a uma palavra apenas, como no texto original (sua referência limita-se a "otoko no ko"), optou-se por escrever "algumas palavras". O problema é que, caso fosse incluída qualquer falha na pronúncia de "meninos", Chī-chan não poderia pronunciar corretamente "meninas" também, uma vez que essas palavras compreendem praticamente os mesmos sons no português (a única diferença é a vogal da última sílaba). De outro modo, caso fosse incluída na fala de Chī-chan, por exemplo, "clianças" (pronúncia comum a crianças pequenas no Brasil), todo o conto teria de ser alterado de modo a expressar a dificuldade da personagem com o " $\mathrm{r}$ ". Assim, a solução encontrada foi omitir a pronúncia incorreta na fala de Chī-chan e transformar "otoko no ko", "meninos", em "algumas palavras" no raciocínio da personagem mãe, indicando essa adaptação na "Nota do tradutor" (transparência).

\section{INFORMAÇÕES RELACIONADAS AO CONTEÚDO DO CONTO E AO TRABALHO DE TRADUÇÃO}

As informações relacionadas ao conteúdo de Kodomo no Hi foram anexadas à tradução em duas seções: "Prólogo do tradutor" e "Glossário". Na primeira, procedeu-se à apresentação de informações relevantes para a compreensão do conto, isto é, falou-se a respeito dos principais feriados japoneses relacionados com as crianças: Festival dos Meninos e Festival das Meninas. Ainda, aproveitou-se essa seção para introduzir dois termos-chave japoneses, koinobori e o-hina-sama, acompanhados de ilustrações feitas por uma ilustradora japonesa. 
A ideia do uso de ilustrações partiu da exposição de Shimon (2006), na qual a autora apresenta figuras que contribuíram para um de seus trabalhos de tradução e na qual ela questiona se não é possível usar ilustrações na tradução de textos literários. Aqui, posiciona-se a favor desse uso nas traduções do japonês para o português, sobretudo para que haja uma melhor compreensão dos substantivos concretos japoneses que não têm correspondentes no Brasil (como koinobori) ou cujos correspondentes brasileiros sejam notadamente diferentes (como no caso de eki no kaisatsuguchi, em que a "catraca da estação" brasileira é bem diferente da japonesa) ${ }^{13}$.

Depois, no "Glossário", apresentaram-se definições e exemplos para os sufixos japoneses -chan e -san. Essa apresentação compreendeu comparações com a língua portuguesa, pois considera-se fundamental incluir referências sobre o universo linguístico que é comum ao leitor, a fim de lhe explicar algo que está fora desse universo. Ainda sobre essa seção, destaca-se que se optou por sua inclusão antes do texto de Teriko em português, e não depois (como em geral se vê nas traduções), porque se considera importante que o leitor parta para o conto já ciente do significado dos itens japoneses incorporados à tradução.

Por último, no que se refere às informações relacionadas ao trabalho de tradução, estas foram anexadas à tradução na "Nota do tradutor". Foram apontadas adaptações, adições e perdas presentes em Dia das Crianças, constituindo essa seção, portanto, o cerne da transparência. Ressalta-se a importância de expor ao leitor também as perdas observadas pelo tradutor no produto final, pois só assim ele pode ter uma noção menos distorcida dos traços do original. Ademais, destaca-se a relevância da numeração de linhas como recurso que, ao mesmo tempo em que permite a indicação precisa das adaptações e adições realizadas, não polui a tradução - posiciona-se a favor de uma tradução transparente e visualmente limpa.

\section{CONSIDERAÇÕES FINAIS}

Neste trabalho, foram apresentadas e discutidas alternativas de tradução para a língua portuguesa do conto japonês Kodomo no Hi, de Teriko, com base em alguns pressupostos sobre a tradução literária e tendo

13 A catraca das estações brasileiras tem uma barreira que se torna móvel ou quando um bilhete é inserido, ou quando os créditos de um cartão são subtraídos; já a catraca das estações japonesas tem uma barreira que só obstrui a passagem quando o usuário tenta atravessá-la sem o uso de bilhetes. 
como lente oito operações básicas envolvidas na tradução literária do japonês para o português. Para encerrar este trabalho, algumas considerações devem ser feitas.

Primeiro, cabe observar que o trabalho de tradução executado desenvolveu-se em condições que podem ser tidas quase como condições ideais de tradução: 1) estabeleceu-se um contato direto com a autora do original japonês; 2) não houve limite de extensão para o trabalho de tradução; 3) não houve nenhuma imposição quanto às escolhas de linguagem e estilo; 4) contou-se com a colaboração de uma ilustradora japonesa para a criação das ilustrações que acompanham o conto. Sabe-se, todavia, que as condições de tradução geralmente são outras, reconhecendo-se que muitas das alternativas defendidas neste estudo dependem da aceitação e apoio das editoras ou de outros tipos de contratantes. Espera-se, pois, que este estudo provoque discussão não apenas nos círculos dos especialistas e tradutores de língua japonesa, mas em esferas mais amplas, de sorte que os aspectos aqui apontados possam ser negociados, sim, entre tradutores e demais envolvidos no trabalho de tradução.

Por fim, é importante notar que este trabalho constitui não mais do que uma pequena contribuição para o estudo da tradução do japonês para o português, sendo muitos ainda os percursos a serem explorados nesse território. A fim de que esse vazio possa ser preenchido e, consequentemente, a fim de que uma tradutologia de língua japonesa possa ganhar contornos mais definidos no Brasil, são necessários tanto mais estudos de apresentação e discussão de alternativas de tradução, como estudos com outras abordagens de pesquisa em tradução (por exemplo, estudos comparativos entre traduções em língua portuguesa já publicadas e originais japoneses).

\section{REFERÊNCIAS}

BATISTA, Valdinei D. Sobre a (in)tradução poética. In: ENCONTRO NACIONAL DE PROFESSORES UNIVERSITÁRIOS DE LÍNGUA, LITERATURA E CULTURA JAPONESA, 5., 1994, São Paulo. Anais... São Paulo: CEJ-USP, 1994. p. 107-115.

BECHARA, Evanildo. Moderna gramática portuguesa. 37. ed. Rio de Janeiro: Nova Fronteira, 2009.

BENJAMIN, Walter. The task of the translator. Trad. Harry Zohn. In: SCHULTE, Rainer; BIGUENET, John (edited by). Theories of translation: an anthology of essays from Dryden to Derrida. Chicago: The University of Chicago Press, 1992. p. 71-82.

CALLOU, Dinah et al. Topicalização e deslocamento à esquerda: sintaxe e prosódia. In: CASTILHO, Ataliba T. de (org.). Gramática do português falado: Volume III: As abordagens. 3. ed. Campinas: Editora da UNICAMP, 2002. p. 315-360.

CAMPOS, Haroldo de. Hagoromo de Zeami. 2. ed. São Paulo: Estação Liberdade, 2006. 
CHINO, Naoko. All about particles: a handbook of Japanese function words. Tokyo: Kodansha, 1991.

CUNHA, Celso; CINTRA, Luís F. L. Nova gramática do português contemporâneo. 5. ed. Rio de Janeiro: Lexikon, 2008.

DNOVELS. DNovels Netto Shōsetsu SNS. Disponível em: <http://www.dnovels.net>. Acesso em: 1 abr. 2010.

HASHIMOTO, Madalena N. Kawabata: pequenas traduções. Estudos Japoneses, São Paulo, n. 6, p. 79-88, 1986.

IORI, Isao et al. Shokyū o oshieru tame no nihongo bunpō handobukku. Tokyo: 3A Nettowāku, 2007 a.

. Chüjōkyūo oshieru tame no nihongo bunpō handobukku. Tokyo: 3A Nettowāku, 2007b.

KAWASHIMA, Atsuko. Particles plus: a complete guide to the usage of particles in modern Japanese. Tokyo: Harcourt Brace Jovanovich Japan, 1992.

KUSANO, Darci Y.; DOI, Elza T. Transcrição e tradução (literal) de Hagoromo. In: CAMPOS, Haroldo de. Hagoromo de Zeami. 2. ed. São Paulo: Estação Liberdade, 2006. p. 55-99.

LANDERS, Clifford E. Literary translation: a practical guide. Clevedon: Multilingual Matters, 2001.

NAGAE, Neide H. Ficção e realidade em Trajetória em noite escura (An'ya kōro) de Shiga Naoya. 1999. 151 f. Dissertação (Mestrado em Língua, Literatura e Cultura Japonesa) - Faculdade de Filosofia, Letras e Ciências Humanas da Universidade de São Paulo, São Paulo, 1999.

. Tradução: meio e fim. In: ENCONTRO NACIONAL DE PROFESSORES UNIVERSITÁRIOS DE LÍNGUA, LITERATURA E CULTURA JAPONESA, 17., 2006, São Paulo. Anais... São Paulo: CEJ-USP, 2006. p. 111-116.

PONTES, Eunice. O tópico no português do Brasil. Campinas: Pontes, 1987.

SEIDENSTICKER, Edward. On trying to translate Japanese. In: BIGUENET, John; SCHULTE, Rainer (edited by). The craft of translation. Chicago: The University of Chicago Press, 1989. p. 142-153.

SHIMON, Meiko. Caracterização da concepção estética de Kawabata Yasunari em Tanagokoro no shōsetsu (Contos que cabem na palma da mão). 1998. 253 f. Dissertação (Mestrado em Língua, Literatura e Cultura Japonesa) - Faculdade de Filosofia, Letras e Ciências Humanas da Universidade de São Paulo, São Paulo, 1998.

. Tradução de Kyoto: um exercício de reflexão sobre a cultura japonesa. In: ENCONTRO NACIONAL DE PROFESSORES UNIVERSITÁRIOS DE LÍNGUA, LITERATURA E CULTURA JAPONESA, 17., 2006, São Paulo. Anais... São Paulo: CEJ-USP, 2006. p. 104-110.

URBANO, Hudinilson. Marcadores conversacionais. In: PRETI, Dino (org.). Análise de textos orais. 6. ed. São Paulo: Humanitas, 2003. p. 93-116.

WAKISAKA, Katsunori (org.). Michaelis: dicionário prático japonês-português. São Paulo: Aliança Cultural Brasil-Japão, 2003.

WARAGAI, Eliane S. As interferências culturais na tradução de textos das religióes de origem japonesa. 2008. 109 f. Dissertação (Mestrado em Língua, Literatura e Cultura Japonesa) - Faculdade de Filosofia, Letras e Ciências Humanas da Universidade de São Paulo, São Paulo, 2008.

Submetido em 17/05/2010

Aceito em 03/02/2011 